
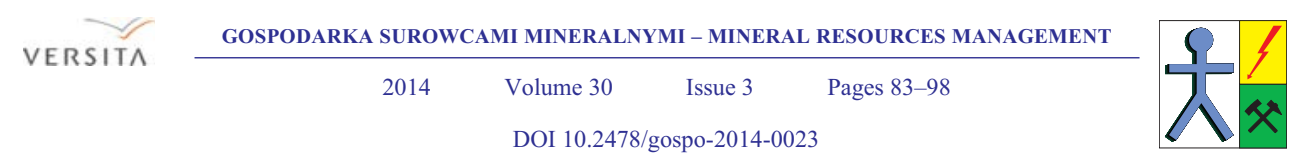

\title{
Filtracja z utworzeniem osadu o małej ściśliwości na siatce filtracyjnej
}

\section{Wprowadzenie}

Proces filtracji znajduje powszechne zastosowanie między innymi w obiegach wodno-mułowych zakładów przemysłowych (np. obiegi wodno-mułowe zakładów przeróbki mechanicznej węgla i rud) oraz oczyszczalniach ścieków komunalnych (Piecuch 2010). W zakładach przemysłowych realizowany jest między innymi w filtrach próżniowych, prasach filtracyjnych oraz wirówkach filtracyjnych - czego modelowym odwzorowaniem jest schemat przedstawiony na rysunku 1 .

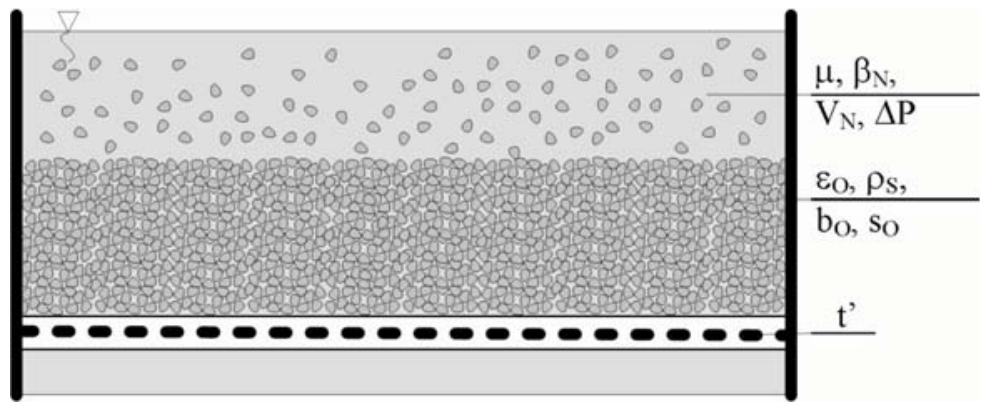

Rys. 1. Schemat procesu filtracji z tworzeniem osadu na siatce filtracyjnej

Fig. 1. A diagram of the filtration process witch the use of a filter mesh

* Prof. dr hab. inż., ** Dr hab. inż., *** Dr, Wydział Inżynierii Lądowej, Środowiska i Geodezji, Politechnika Koszalińska, Koszalin; e-mail: tadeusz.piecuch@tu.koszalin.pl 
Problematyką ogólnie pojętej filtracji zajmuje się ogromna ilość zespołów badawczych. Niemniej jednak pionierem tych badań był francuski uczony Darcy i jego następcy, co można określić francuską szkołą filtracji (m.in. Le Lec 1962). Oczywiście, wiele zespołów badawczych zajęło się tą problematyką także w innych krajach, między innymi w USA, Holandii w Niemczech i Rosji (Dahlstrom i Nickolaus 1956; Hertjess 1948; Hertjess i Haas 1949). W Polsce problematyką filtracji także zajmuje się wiele ośrodków, a w przeszłości pionierskie badania w tym zakresie prowadziła szkoła naukowa prof. Romana Kocha z Politechniki Wrocławskiej, a następnie Śląska Szkoła Naukowa prof. Jerzego Pikonia i jego następców (prof. J. Madej, prof. T. Zabłocki, prof. J. Hehlemann, prof. M. Palica i inni). Od wielu lat problematyką filtracji zajmuje się również T. Piecuch i jego zespół. Badania procesu filtracji prowadził w Politechnice Śląskiej (1969-1978), Politechnice Częstochowskiej (1978-1987), a obecnie w Politechnice Koszalińskiej (od 1988), i obejmują one zarówno zagadnienia doświadczalne (Piecuch 1978) jak i teoretyczne (Piecuch 2009; Sówka i Piecuch 1974; Piekarski 2009, 2011; Piekarski i Dąbrowski 2011).

Przegrodą porowatą w procesie filtracji może być membrana, co odnosi się do niezwykle subtelnej odmiany procesu zwanej również nanofiltracją (filtracją jonową). Badania takie zapoczątkował i rozwinął w Politechnice Wrocławskiej prof. Tomasz Winnicki, a kontynuuje zespół prof. Jacka Wiśniewskiego (Wiśniewski i in. 2013), natomiast w Politechnice Śląskiej prof. Michał Bodzek i inni (Bodzek i Konieczny 2011; Mielczarek i Bohdziewicz 2011). Problematyka nanofiltracji to oddzielne zagadnienie teoretyczne inne niż klasyczna filtracja. Wreszcie filtracja może zachodzić także na złożach biologicznych, co także łączy się z towarzyszącą naturalną biosorpcją (Gajewska i Obarska-Pempkowiak 2009; Malczewska 2008; Obarska-Pempkowiak i in. 2011; Rodziewicz i in. 2011).

Niniejsza publikacja stanowi kontynuację teoretycznej publikacji (Piecuch i in. 2013), w której autorzy zajmują się wyprowadzeniem końcowych równań filtracji dla osadów o różnej ściśliwości. Klasyczna teoria filtracji oparta jest na znanym wyjściowym równaniu Darcy'ego, o postaci jak niżej:

$$
\dot{V}=\frac{\Delta p}{R}=\frac{\Delta p}{\alpha \frac{L}{A}}=\frac{\Delta p}{\frac{\mu}{k} \frac{L}{A_{F}}}
$$

które jest równaniem przepływu płynu przez przegrodę porowatą cieczy (stanowiącej układ jednofazowy), a nie mieszaniny. W tym równaniu Darcy’ego wartość współczynnika przepuszczalności $k$ określają m.in. empiryczna formuła Kozeny, Carman, Pouiseillea, Orlicka, jak niżej:

$$
k=\frac{b_{O}}{\Delta p^{s_{O}}}
$$


Wprowadzając powyższy empiryczny zapis (2) do równania (1), a także uwzględniając, że wszystkie cząstki stałe tworzące mieszaninę cieczy i ciała stałego o objętości $V_{N}$ i zagęszczeniu $\beta_{N}$ utworzą osad na siatce filtracyjnej, T. Piecuch $(2009,2010)$ przedstawił równanie filtracji z tworzeniem osadu na siatce filtracyjnej. Stało się tak dlatego, że do równania przepływu płynu przez ośrodek porowaty według Darcy’ego wprowadził wskaźnik składu mieszanin jakim jest zagęszczenie $\beta_{N}$. Tak więc ogólne równanie filtracji mieszaniny przez siatkę filtracyjną przyjmuje postać jak niżej:

$$
\dot{V}=\frac{\Delta P}{t}
$$

Opór ogólny przedstawiony w mianowniku jest sumą oporu ogólnego siatki filtracyjnej oraz osadu gromadzonego na tej siatce. Równanie (3) odnosi się do przepływu objętościowego, który jest stosunkiem objętości do czasu przepływu medium, a więc równanie (3) można przedstawić $\mathrm{w}$ postaci:

$$
\frac{V}{t}=\frac{\Delta P}{t}
$$

Przyjmując, że w danym urządzeniu filtracyjnym (np. filtrze próżniowym lub prasie filtracyjnej) panuje stałe ciśnienie $\Delta P=$ const., to równanie filtracji przyjmie postać:

$$
\frac{d V}{d t}=\frac{\Delta P}{t}
$$

$\mathrm{W}$ równaniu (5) przepływ chwilowy medium maleje, bowiem przy zachowaniu stałego ciśnienia wzrasta grubość warstwy filtracyjnej, co powoduje zwiększenie wartości oporu ogólnego. W przypadku procesu filtracji ze zmiennym ciśnieniem, natężenie przepływu medium jest stałe, gdyż w odniesieniu do praktyki oznacza to, że ciśnienie w danym urządzeniu filtracyjnym na skutek zwiększania się grubości warstwy osadu filtracyjnego powinno w miarę trwania procesu wzrastać proporcjonalnie do wzrostu oporu filtracyjnego, co można zapisać:

$$
\frac{V}{t}=\frac{d P}{a^{\prime}{ }_{t}\left[t^{\prime} \frac{\mu}{A_{F}}+\frac{\mu}{b_{O}} \Delta P^{s_{O}} \frac{V_{N} \beta_{N}}{A_{F}^{2}\left(1-\varepsilon_{O}\right) \rho_{S}}\right] d t}
$$

Powyżej przedstawiono dwa zasadnicze równania filtracji: przy stałym ciśnieniu ale zmiennym przepływie (5) oraz równanie przy zmiennym ciśnieniu lecz stałym przepływie (6). Występująca w równaniach (5) oraz (6) ściśliwość osadu filtracyjnego, oz- 
naczana jest współczynnikiem ściśliwości $s_{O}$, który teoretycznie może przyjmować wartość od $s_{O}=0$ (brak ściśliwości) do $s_{O}=1$ (pełna ściśliwość). Często w wywodach teoretycznych dla uproszczenia przyjmuje się brak ściśliwości, tj. $s_{O}=0$, stąd równanie (5) przyjmuje postać:

$$
\frac{d V}{d t}=\frac{\Delta P}{t}
$$

Natomiast równanie (6) można zapisać:

$$
\frac{V}{t}=\frac{d P}{a^{\prime}{ }_{t}\left[t^{\prime} \frac{\mu}{A_{F}}+\frac{\mu}{b_{O}} \frac{V_{N} \beta_{N}}{A_{F}^{2}\left(1-\varepsilon_{O}\right) \rho_{S}}\right] d t}
$$

Równanie różniczkowe (7) po scałkowaniu przyjmie postać:

$$
\Delta P t=\left(t^{\prime} \frac{\mu}{A_{F}} V+\frac{\mu}{b_{O}} \frac{\beta_{N}}{A_{F}^{2}\left(1-\varepsilon_{O}\right) \rho_{S}} V^{2}\right) d t
$$

W literaturze można spotkać zapis uproszczony o postaci (równanie Rutha):

$$
C_{2} t=C_{1} V+V^{2}
$$

gdzie:

$t$ - czas filtracji.

W odniesieniu do procesu filtracji, a nie tylko przepływu płynu przez przegrodę porowatą, w równaniu (10) wartości stałych $C_{1}$ oraz $C_{2}$ przyjmują według Piecucha zapis:

$$
C_{1}=2 A_{F} \beta_{\mathrm{N}}^{-1} b_{O} \rho_{S} t^{\prime}\left(1-\varepsilon_{O}\right)
$$

oraz:

$$
C_{2}=2 A_{F}^{2} \Delta P \beta_{\mathrm{N}}^{-1} \mu^{-1} b_{O} \rho_{S} t^{\prime}\left(1-\varepsilon_{O}\right)
$$

Natomiast rozwiązanie równania (8), a więc równania przy zmiennym ciśnieniu $(d P / d t)$, gdzie wprowadzono współczynnik korekcyjny jednostki czasu $a_{t}^{\prime}$, po scałkowaniu ma postać: 


$$
\ln (t)=\frac{\Delta P}{a^{\prime}{ }_{t}\left[t^{\prime} \frac{\mu}{A_{F}}+\frac{\mu}{b_{O}} \frac{V_{N} \beta_{N}}{A_{F}^{2}\left(1-\varepsilon_{O}\right) \rho_{S}}\right]}
$$

\section{Analiza teoretyczna procesu filtracji przy założeniu ściśliwości osadu}

Rozważaniami teoretycznymi nad problemem ściśliwości osadu filtracyjnego obok autorów publikacji zajmował się także zespół M. Palicy (Kocurek i Palica 2002; Palica i Kocurek 2003; Palica i in. 2008, 2009, 2010a, 2010b), który określał podatność porowatości na ciśnienie wprowadzając pojęcie tak zwanego ciśnienia kontaktowego, przy czym w swych rozważaniach teoretycznych M. Palica podzielił osad filtracyjny na warstwy (Palica i Kocurek 2001). Natomiast autorzy publikacji, wychodząc z ogólnego równania filtracji przy zmiennym ciśnieniu (6) i zakładając, że osad jest ściśliwy $\left(s_{O} \neq 0\right)$ przedstawili sposób rozwiązania oraz równania końcowe procesu filtracji dla różnych (dużych) wartości współczynnika ściśliwości so, równych odpowiednio: 1/3, 1/2 oraz 2/3 (Piecuch i in. 2013).

W niniejszej publikacji przedstawiono sposób rozwiązania ogólnego równania filtracji przy zmiennym ciśnieniu (6) zakładając, że osad również jest ściśliwy, a wartość współczynnika ściśliwości so jest niska i wynosi: 1/4, 1/5 oraz 1/6.

W tym celu przyjęto stałe $\mathrm{A}, \mathrm{B}$ oraz $\mathrm{C}$ dla matematycznego zapisu ogólnego równania filtracji:

- stała $A$

$$
A=t^{\prime} \frac{\mu}{A_{F}}
$$

- stała $C$

$$
C=\frac{\mu V_{N} \beta_{N}}{b_{O} A_{F}^{2}\left(1-\varepsilon_{O}\right) \rho_{S}}
$$

- stała $B=s_{O}$

Uwzględniając powyższe stałe $A, B$ oraz $C$ matematyczny zapis równania filtracji, gdy $a_{t}^{\prime}=1$ przyjmie postać: 


$$
\frac{V}{t}=\frac{1}{A+C(\Delta P)^{B}} \frac{d P}{d t}
$$

Wprowadzając nową zmienną $x=\Delta P$ oznaczającą zmienne ciśnienie (i stąd $d x=d P$ oznacza różniczkę ciśnienia), otrzymuje się model matematyczny procesu filtracji opisany równaniem różniczkowym:

$$
\frac{V}{t}=\frac{1}{A+C x^{B}} \frac{d x}{d t}
$$

Jest to równanie różniczkowe o zmiennych rozdzielonych, które można zapisać w postaci równości różniczek:

$$
V \frac{d t}{t}=\frac{d x}{A+C x^{B}}
$$

Całkowanie równania różniczkowego jest jedną z nielicznych metod bezpośredniego znajdowania rozwiązania, tj. jego całki ogólnej. Zatem, w wyniku obustronnego całkowania równości:

$$
V \int \frac{d t}{t}=\int \frac{d x}{A+C x^{B}}
$$

otrzymuje się rozwiązanie $V \ln (t)=F(x)$, gdzie:

$$
I=F(x)=\int \frac{d x}{A+C x^{B}} ; \quad 0<B \leq 1
$$

gdzie:

$A, C-$ określone stałe.

Jest to całka ogólna równania różniczkowego procesu filtracji. Poniżej przedstawiono rozwiązanie całki określonej równaniem (19) dla szczególnych przypadków współczynników ściśliwości $B$.

\subsection{Współczynnik ściśliwości $B=1 / 4$}

Zatem $x^{B}=\sqrt[4]{x}$, stąd całka (20) przyjmuje postać:

$$
I=F(x)=\int \frac{d x}{A+C \sqrt[4]{x}}
$$


Po podstawieniu $\sqrt[4]{x}=u$, to wtedy $x=u^{4}$, stąd:

$$
d x=4 u^{3} d u
$$

Całkę (21) sprowadza się do całki z funkcji wymiernej o postaci:

$$
I=4 \int \frac{u^{3} d u}{A+C u}
$$

Funkcję podcałkową:

$$
f(u)=\frac{u^{3}}{A+C u}
$$

która jest niewłaściwą funkcją wymierną, przedstawia się w postaci sumy wielomianu i ułamka prostego pierwszego rodzaju:

$$
\frac{u^{3}}{A+C u}=\frac{1}{C} u^{2}-\frac{A}{C^{2}} u+\frac{A^{2}}{C^{3}}-\frac{A^{3}}{C^{3}} \frac{1}{A+C u}
$$

Uwzględniając rozkład (25) w całce (23), a następnie całkując:

$$
\int \frac{u^{3}}{A+C u} d u=\frac{1}{3 C} u^{3}-\frac{A}{2 C^{2}} u^{2}+\frac{A^{2}}{C^{3}} u-\frac{A^{3}}{C^{3}} \ln |A+C u|+D
$$

i po powrocie do wyjściowej zmiennej $x$, po podstawieniu za $u=\sqrt[4]{x}$ otrzymuje się rozwiązanie całki (21). Zatem całka ogólna (20) dla $B=0,25$ wyraża się ogólnym wzorem w zapisie matematycznym:

$$
F(x)=\int \frac{d x}{A+C \sqrt[4]{x}}=\frac{4}{3 C} \sqrt[4]{x^{3}}-\frac{2 A}{C^{2}} \sqrt{x}+\frac{4 A^{2}}{C^{3}} \sqrt[4]{x}-\frac{4 A^{2}}{C^{4}} \ln |A+C \sqrt[4]{x}|+D
$$

gdzie:

$D$ - stała całkowania, którą można wyznaczyć z warunku początkowego.

Natomiast wzór (27) w zapisie fizykalnym równania filtracji przy zmiennym ciśnieniu dla współczynnika ściśliwości $s_{O}=0,25$ przyjmie zapis: 


$$
\begin{gathered}
V \cdot \ln (t)=\frac{4 b_{O} A_{F}^{2}\left(1-\varepsilon_{O}\right) \rho_{S} \sqrt[4]{\Delta P^{3}}}{3 \mu V_{N} \beta_{N}}-\frac{2 t^{\prime} \mu \sqrt{\Delta P}}{A_{F}\left(\frac{\mu V_{N} \beta_{N}}{b_{O} A_{F}^{2}\left(1-\varepsilon_{O}\right) \rho_{S}}\right)^{2}}+ \\
+\frac{4\left(t^{\prime} \frac{\mu}{A_{F}}\right)^{2} \sqrt[4]{\Delta P}}{\left(\frac{\mu V_{N} \beta_{N}}{b_{O} A_{F}^{2}\left(1-\varepsilon_{O}\right) \rho_{S}}\right)^{3}}-\frac{4\left(t^{\prime} \frac{\mu}{A_{F}}\right)^{2}}{\left(\frac{\mu V_{N} \beta_{N}}{b_{O} A_{F}^{2}\left(1-\varepsilon_{O}\right) \rho_{S}}\right)^{4}} \ln \left|t^{\prime} \frac{\mu}{A_{F}}+\frac{\mu V_{N} \beta_{N} \sqrt[4]{\Delta P}}{b_{O} A_{F}^{2}\left(1-\varepsilon_{O}\right) \rho_{S}}\right|+D
\end{gathered}
$$

\subsection{Współczynnik ściśliwości $B=1 / 5$}

Zatem $x^{B}=\sqrt[5]{x}$, stąd całka (20) przyjmuje postać:

$$
I=F(x)=\int \frac{d x}{A+C \sqrt[5]{x}}
$$

Po podstawieniu $\sqrt[5]{x}=u$, to wtedy $x=u^{5}$, a więc:

$$
d x=5 u^{4} d u
$$

Całkę (29) sprowadza się do całki z funkcji wymiernej postaci:

$$
I=5 \int \frac{u^{4} d u}{A+C u}
$$

Funkcję podcałkową:

$$
f(u)=\frac{u^{4}}{A+C u}
$$

która jest wymierną funkcją niewłaściwą, przedstawia się w postaci sumy wielomianu i ułamka prostego pierwszego rodzaju:

$$
\frac{u^{4}}{A+C u}=\frac{1}{C} u^{3}-\frac{A}{C^{2}} u^{2}+\frac{A^{2}}{C^{3}} u-\frac{A^{3}}{C^{4}}+\frac{A^{4}}{C^{4}} \frac{1}{A+C u}
$$


Uwzględniając rozkład (33) w całce (31), a następnie całkując i wracając do wyjściowej zmiennej $x$, tj. po podstawieniu za $u=\sqrt[5]{x}$ otrzymuje się rozwiązanie całki (29):

$F(x)=\int \frac{d x}{A+C \sqrt[5]{x}}=\frac{5}{4 C} \sqrt[5]{x^{4}}-\frac{5 A}{3 C^{2}} \sqrt[5]{x^{3}}+\frac{5 A^{2}}{2 C^{3}} \sqrt[5]{x^{3}}-\frac{5 A^{3}}{C^{4}} \sqrt[5]{x}+\frac{5 A^{4}}{C^{5}} \ln |A+C \sqrt[5]{x}|+D$

gdzie:

$D$ - stała całkowania.

Natomiast równanie filtracji o postaci (34) przyjmie fizykalny zapis równania filtracji dla współczynnika ściśliwości $s_{O}$ równy 0,2 jak niżej:

$$
\begin{gathered}
V \cdot \ln (t)=\frac{5 b_{O} A_{F}^{2}\left(1-\varepsilon_{O}\right) \rho_{S} \sqrt[5]{\Delta P^{4}}}{4 \mu V_{N} \beta_{N}}-\frac{5\left[b_{O} A_{F}^{2}\left(1-\varepsilon_{O}\right) \rho_{S}\right]^{2} t^{\prime} \sqrt[5]{\Delta P^{3}}}{3 A_{F}^{2} \mu\left(V_{N} \beta_{N}\right)^{2}}+ \\
+\frac{5\left[b_{O} A_{F}^{2}\left(1-\varepsilon_{O}\right) \rho_{S}\right]^{3} t^{\prime 2} \sqrt[5]{\Delta P^{3}}}{2 A_{F}^{2} \mu\left(V_{N} \beta_{N}\right)^{3}}-\frac{5\left[b_{O} A_{F}^{2}\left(1-\varepsilon_{O}\right) \rho_{S}\right]^{4} t^{\prime 3} \sqrt[5]{\Delta P}}{A_{F}^{3} \mu\left(V_{N} \beta_{N}\right)^{4}}+ \\
+\frac{5\left[b_{O} A_{F}^{2}\left(1-\varepsilon_{O}\right) \rho_{S}\right]^{4} t^{4}}{A_{F}^{4} \mu\left(V_{N} \beta_{N}\right)^{5}} \ln \left|t^{\prime} \frac{\mu}{A_{F}}+\frac{\mu V_{N} \beta_{N} \sqrt[5]{\Delta P}}{b_{O} A_{F}^{2}\left(1-\varepsilon_{O}\right) \rho_{S}}\right|+D
\end{gathered}
$$

\subsection{Współczynnik ściśliwości $B=1 / 6$}

Zatem $x^{B}=\sqrt[6]{x}$, stąd całka (20) przyjmuje postać:

$$
I=F(x)=\int \frac{d x}{A+C \sqrt[6]{x}}
$$

Po podstawieniu $\sqrt[6]{x}=u$, stąd $x=u^{6}$, a więc:

$$
d x=6 u^{5} d u
$$

Całkę (36) sprowadza się do całki z funkcji wymiernej o postaci: 


$$
I=6 \int \frac{u^{5} d u}{A+C u}
$$

Funkcję podcałkową:

$$
f(u)=\frac{u^{5}}{A+C u}
$$

przedstawia się w postaci sumy wielomianu i ułamka prostego pierwszego rodzaju:

$$
\frac{u^{5}}{A+C u}=\frac{1}{C} u^{4}-\frac{A}{C^{2}} u^{3}+\frac{A^{2}}{C^{3}} u^{2}-\frac{A^{3}}{C^{4}} u+\frac{A^{4}}{C^{5}}-\frac{A^{5}}{C^{6}} \frac{1}{A+C u}
$$

Uwzględniając rozkład (40) w całce (38), a następnie całkując i wracając do wyjściowej zmiennej $x$, tj. po podstawieniu za $u=\sqrt[6]{x}$, otrzymuje się rozwiązanie całki (36):

$$
\begin{gathered}
F(x)=\int \frac{d x}{A+C \sqrt[6]{x}}=\frac{6(\sqrt[6]{x})^{5}}{5 C}-\frac{3 \sqrt[3]{x^{2}}}{2 C^{2}}+\frac{A^{2} \sqrt{x}}{2 C^{3}}- \\
-\frac{3 A^{3} \sqrt[3]{x}}{C^{4}}+\frac{6 A^{4} \sqrt[6]{x}}{C^{5}}-\frac{6 A^{5}}{C^{6}} \ln |A+C \sqrt[6]{x}|+D
\end{gathered}
$$

gdzie:

$D$ - stała całkowania wyznaczana z warunku początkowego.

Powyższe równanie (41) jest więc zapisem równania filtracji przy zmiennym ciśnieniu dla osadów ściśliwych przy współczynniku ściśliwości $s_{O}=1 / 6$. To samo równanie filtracji dla tych samych założeń przyjmie postać fizykalną:

$$
\begin{gathered}
V \cdot \ln (t)=\frac{6 \mu V_{N} \beta_{N}(\sqrt[6]{\Delta P})^{5}}{5 b_{O} A_{F}^{2}\left(1-\varepsilon_{O}\right) \rho_{S}}-\frac{3\left[b_{O} A_{F}^{2}\left(1-\varepsilon_{O}\right) \rho_{S}\right]^{2} \sqrt[3]{\Delta P^{2}}}{2\left(\mu V_{N} \beta_{N}\right)^{2}}+ \\
+\frac{t^{\prime 2}\left[b_{O} A_{F}^{2}\left(1-\varepsilon_{O}\right) \rho_{S}\right]^{3} \sqrt{\Delta P}}{2 A_{F}^{2} \mu\left(V_{N} \beta_{N}\right)^{3}}-\frac{3 t^{\prime 3}\left[b_{O} A_{F}^{2}\left(1-\varepsilon_{O}\right) \rho_{S}\right]^{4} \sqrt[3]{\Delta P}}{A_{F}^{3} \mu\left(V_{N} \beta_{N}\right)^{4}}+\frac{6 t^{\prime 4}\left[b_{O} A_{F}^{2}\left(1-\varepsilon_{O}\right) \rho_{S}\right]^{5} \sqrt[6]{\Delta P}}{A_{F}^{4} \mu\left(V_{N} \beta_{N}\right)^{5}}- \\
-\frac{6 t^{\prime 5}\left[b_{O} A_{F}^{2}\left(1-\varepsilon_{O}\right) \rho_{S}\right]^{6}}{A_{F}^{4} \mu\left(V_{N} \beta_{N}\right)^{6}} \ln \left|t^{\prime} \frac{\mu}{A_{F}}+\frac{\mu V_{N} \beta_{N} \sqrt[6]{\Delta P}}{b_{O} A_{F}^{2}\left(1-\varepsilon_{O}\right) \rho_{S}}\right|+D
\end{gathered}
$$




\section{Podsumowanie - wnioski}

Spośród wielu wariantów procesu filtracji, niniejsza analiza teoretyczna odnosi się do konkretnego i praktycznego przypadku takiego procesu. Model ten ma odniesienie do filtracji mieszaniny, która napływa na siatkę filtracyjną i tworzy osad.

Filtrację można rozpatrywać jako filtrację mieszaniny napływającej na złoże porowate, usypane na przegrodzie filtracyjnej (siatce lub ruszcie) z tworzeniem osadu filtracyjnego na złożu, ze zjawiskiem kolmatacji w złożu i bez tworzenia osadu na złożu, jak z jednym i drugim - to jest z tworzeniem osadu na złożu i równoczesną kolmatacją. Rozważania można jeszcze bardziej uściślić, odrzucając upraszczające założenie, że zagęszczenie filtratu jest równe zero, a więc przyjąć, że filtrat zawiera cząstki fazy stałej, które przedostały się w procesie filtracji przez złoże filtracyjne i przez siatkę (ruszt). Oznacza to wprowadzenie określonych współczynników korekcyjnych odnośnie osadu wytworzonego na złożu, ziaren mieszaniny, które skolmatowały, a więc zmniejszyły porowatość złoża i pewnej niewielkiej ilości ziaren mieszaniny, które przedostały się do filtratu. Wówczas w bazowym ogólnym równaniu filtracji (przykładowo równania 3) wystapi opór złoża filtracyjnego obok oporu siatki filtracyjnej oraz oporu osadu.

Przeprowadzona w niniejszej pracy analiza teoretyczna wskazuje, że:

- nie można sformułować jednego uniwersalnego równania filtracji, w którym występuje jako parametr współczynnik ściśliwości $s_{O}$ i za ten współczynnik do takiego jednego równania podstawiać liczbową wartość tego współczynnika i wyliczać na przykład przepływ medium w tym procesie,

- chcąc wykorzystać główne uniwersalne równania filtracji np. (5) lub (6) należy je przekształcić w nową formułę zapisu końcowego - tak jak to przedstawiono w niniejszej publikacji dla osadów ściśliwych, gdy współczynnik ściśliwości $s_{O}$ wynosi 1/4, 1/5 oraz 1/6, a dopiero potem korzystać z tych nowych postaci równan,

- taką samą analizę teoretyczną ze względu na ściśliwość można przeprowadzić dla równania filtracji przy stałym ciśnieniu i jednocześnie przy zmiennym przepływie równanie (5) - co będzie przedmiotem dalszych badań i rozważań autorów.

\section{Symbolika oznaczeń}

\begin{tabular}{|c|l|c|}
\hline$R$ & $\begin{array}{l}\text { całkowity opór przegrody porowatej } \\
\text { total resistance of the porous barrier }\end{array}$ & {$\left[\mathrm{N} \cdot \mathrm{s} / \mathrm{m}^{5}\right]$} \\
\hline$\Delta P$ & $\begin{array}{l}\text { spadek ciśnienia } \\
\text { pressure drop }\end{array}$ & {$\left[\mathrm{N} / \mathrm{m}^{2}\right]$} \\
\hline$t^{\prime}$ & $\begin{array}{l}\text { opór średni siatki filtracyjnej } \\
\text { average resistance of the filter mesh }\end{array}\left[\mathrm{m}^{-1}\right]$ \\
\hline
\end{tabular}




\begin{tabular}{|c|c|c|}
\hline$\mu$ & $\begin{array}{l}\text { współczynnik lepkości dynamicznej zawiesiny } \\
\text { dynamic viscosity factor for the emulsion }\end{array}$ & {$\left[\mathrm{N} \cdot \mathrm{s} / \mathrm{m}^{2}\right]$} \\
\hline$A_{F}$ & $\begin{array}{l}\text { powierzchnia złoża } \\
\text { layer area }\end{array}$ & {$\left[\mathrm{m}^{2}\right]$} \\
\hline$b_{O}$ & $\begin{array}{l}\text { wartość stała dla osadu } \\
\text { sediment constant }\end{array}$ & {$[\mathrm{N}]$} \\
\hline$s_{O}$ & $\begin{array}{l}\text { współczynnik ściśliwości osadu } \\
\text { sediment compressibility factor }\end{array}$ & {$[-]$} \\
\hline $\mathrm{V}_{\mathrm{N}}$ & $\begin{array}{l}\text { objętość nadawy } \\
\text { feed volume }\end{array}$ & {$\left[\mathrm{m}^{3}\right]$} \\
\hline$\beta_{N}$ & $\begin{array}{l}\text { zagęszczenie fazy stałej w dopływie } \\
\text { solid-phase condensation in the inflow }\end{array}$ & {$\left[\mathrm{kg} / \mathrm{m}^{3}\right]$} \\
\hline$\varepsilon_{O}$ & $\begin{array}{l}\text { porowatość osadu } \\
\text { sediment porosity }\end{array}$ & {$[-]$} \\
\hline$\rho_{S}$ & $\begin{array}{l}\text { gęstość zatrzymanej fazy stałej } \\
\text { density of the screened solid phase }\end{array}$ & {$\left[\mathrm{kg} / \mathrm{m}^{3}\right]$} \\
\hline$L$ & $\begin{array}{l}\text { grubość osadu } \\
\text { height of sediment layer }\end{array}$ & {$[\mathrm{m}]$} \\
\hline$\alpha$ & $\begin{array}{l}\text { opór właściwy osadu } \\
\text { specific resistance of compressible sediment layer }\end{array}$ & {$\left[\mathrm{N} \cdot \mathrm{s} / \mathrm{m}^{4}\right]$} \\
\hline K & $\begin{array}{l}\text { współczynnik przepuszczalności } \\
\text { permeability coefficient }\end{array}$ & {$\left[\mathrm{m}^{2}\right]$} \\
\hline$\dot{V}$ & $\begin{array}{l}\text { wydatek objętościowy } \\
\text { volume output }\end{array}$ & {$\left[\mathrm{m}^{3} / \mathrm{s}\right]$} \\
\hline
\end{tabular}

\section{LITERATURA}

Bodzek, M. i Konieczny, K. 2011. Membrane Techniques in the Removal of Inorganic Anionic Micropollutants from Water Environment - State of the Art. Archives of Environmental Protection 37(2), s. 15-29.

Chmiel, K. i Palica, M. 2005. Modelowanie procesu biofiltracji. Rocznik Ochrona Środowiska - Annual Set the Environment Protection 7, s. 143-175.

Ciborowski, J. 1965. Inżynieria chemiczna. Warszawa: Wyd. Nauk. PWN, $611 \mathrm{s.}$

Dahlstrom, D.A. i Nickolaus, N. 1956. Theory and practice of continuous pressure filtration. Chemical Engineering Progress 3, s. 87-93.

Gajewska, M. i Obarska-Pempkowiak, H. 2009. 20 lat doświadczeń z eksploatacji oczyszczalni hydrofitowych w Polsce. Rocznik Ochrona Środowiska - Annual Set the Environment Protection 11, s. 875-888.

Hertjess, P. M. 1948. Industrial filtration. Department of Chemical Engineering. Technical University Delft, s. 254-259.

Hertjess, P. M. i Haas, H. 1949. Studies in filtration Recoil Trav. Chim, Pays-Bas 6, s. 361-382.

Kocurek, J. i Palica, M. 2002. Rozdzielanie zawiesin ciał stałych w cieczach na drodze filtracji z kompresją tworzonego osadu. Część 1. Teoretyczny opis filtracji z równoczesną kompresją osadu. Rocznik Ochrona Środowiska - Annual Set the Environment Protection 4, s. 133-166. 
Le Lec, P. 1962. Variatons de permeabilite des gateax de filtration. Genie Chimique 3, s. 61-83.

Malczewska, B. 2008. Sewage sludge rheological properties variability in dependence of drawing sludge samples at different times. Archives of Environmental Protection 34(4), s. 109-116.

Mielczarek, K. i Bohdziewicz, J. 2011. Performance prediction of ultrafiltration of post process coke wastewater based on the assumption of hydraulic filtration resistance model. Archives of Environmental Protection 37(4), s. $107-118$

Obarska-Pempkowiak i in. 2011 - Obarska-Pempkowiak, H., Gajewska, M., Wojciechowska, E. i Stosik, M. 2011. Systemy hydrofitowe do oczyszczania spływów powierzchniowych w rejonie Zatoki Gdańskiej. Rocznik Ochrona Środowiska - Annual Set the Environment Protection 13, s. 173-186.

Palica, M. i Kocurek, J. 2001. Wybrane zagadnienia teorii filtracji i kompresji osadów. Gliwice: Wydawnictwo Politechniki Śląskiej, 139 s.

Palica, M. i Kocurek, J. 2003. Rozdzielanie zawiesin ciał stałych w cieczach na drodze filtracji z kompresją tworzonego osadu. Część 2. Rocznik Ochrona Środowiska - Annual Set The Environment Protection 5, s. $87-122$.

Palica i in. 2007 - Palica, M., Grotek, M., Niemirowski, J. 2007. Opis odwadniania zawiesiny zrzutowej po wirówce filtracyjno-sedymentacyjnej BIRDa modelem SORENSENA. Rocznik Ochrona Środowiska Annual Set The Environment Protection 9, s. 133-158.

Palica i in. 2008 - Palica, M., Pęczek, K., Kurowski, Ł. i Niemirowski, J. 2008. Periodyczna filtracja wirowa zawiesiny zrzutowej po wirówkach BIRDa zawierającej dodatek flokulantu MAGNAFLOC 336. Rocznik Ochrona Środowiska - Annual Set The Environment Protection 10, s. 275-288.

Palica i in. 2009 - Palica, M., Gierczycki, A. i Lemanowicz, M. 2009. Własności filtracyjne zawiesiny po wirówkach DECANTER po dodaniu flokulantu MAGNAFLOC 919. Rocznik Ochrona Środowiska - Annual Set The Environment Protection 11, s. 823-836.

Palica i in. 2010a - Palica, M., Wątor, K., Thullie, J. i Kurowski, Ł. 2010. Odwadnianie szlamu węglowego na drodze periodycznej filtracji wirowej. Rocznik Ochrona Środowiska - Annual Set The Environment Protection 12 , s. $489-502$

Palica i in. 2010b - Palica, M., Spyrka, W. i Adamczyk, M. 2010. Testy filtracji ciśnieniowej zawiesiny odpadowej z odmulnika DORRa. Rocznik Ochrona Środowiska - Annual Set The Environment Protection 13, s. $1885-1201$

Pawęska, K. i Kuczewski, K. 2013. The small wastewater treatment plants-hydrobotanical systems in Environmental Protection. Archives of Environmental Protection 1(39), s. 39-58.

Piecuch, T. 1978. Badania procesu filtracji ciśnieniowej poflotacyjnych odpadów rud miedzi. Rudy i Metale Nieżelazne 12, s. 639-643.

Piecuch, T. 2009. Równanie Darcy jako podstawa analizy teoretycznej szczególnych przypadków procesu filtracji. Rocznik Ochrona Środowiska - Annual Set The Environment Protection 11, s. 299-318.

Piecuch, T. 2010. Technika wodno-mułowa. Urzadzenia i procesy. Warszawa, Państwowe Wydawnictwo Naukowo-Techniczne, $504 \mathrm{~s}$.

Piecuch i in. 2013 - Piecuch, T., Piekarski, J. i Malatyńska, G. 2013. The Equation Describing the Filtration Process with Compressible Sediment Accumulation on a Filter Mesh. Archives of Environmental Protection. 1(39), s. 39-58.

Piekarski, J. 2009. Colmatation blockage during gravitational filtration process of coal suspension on sand bed. Mineral Resources Management 25, s. 121-133.

Piekarski, J. 2009. Analiza wybranych parametrów kolmatacji w procesie filtracji grawitacyjnej. Rocznik Ochrona Środowiska - Annual Set The Environment Protection 11, s. 421-438.

Piekarski, J. i Dąbrowski, T. 2011. Investigations on colmatation during filtration process on the porous deposit. Polish Journal of Environmental Studies 10, s. 51-56.

Piekarski, J. 2011. Zastosowanie metod numerycznych do modelowania procesu filtracji grawitacyjnej. Rocznik Ochrona Środowiska - Annual Set The Environment Protection 13, s. 315-332.

Rodziewicz i in. 2011 - Rodziewicz, J., Filipkowska, U. i Janczukowicz, W. 2011. Zastosowanie tarczowych złóż biologicznych do oczyszczania ścieków z hodowli ryb. Rocznik Ochrona Środowiska - Annual Set The Environment Protection 13, s. 1233-1244. 
Sówka, J. i Piecuch, T. 1974. Stan badań teoretycznych i praktycznych nad procesem filtracji zawiesin. Zeszyty Naukowe Politechniki Ślaskiej 403(60), s. 13-26.

Wiśniewski i in. 2013 - Wiśniewski, J., Kabsch-Korbutowicz, M. i Łakomska, S. 2013. Usuwanie bromków i bromianów z wody w procesie wymiany anionów przez membranę jonowymienną. Rocznik Ochrona Środowiska - Annual Set The Environment Protection 15, s. 1260-1279.

\title{
FILTRACJA Z UTWORZENIEM OSADU O MALEJ ŚCIŚLIWOŚCI NA SIATCE FILTRACYJNEJ
}

\author{
Słowa kluczowe
}

analizy teoretyczne, proces filtracji, ściśliwość osadu

\section{Streszczenie}

Publikacja przedstawia metodę określenia końcowych równań procesu filtracji przy stałym przepływie V/t dla różnych wartości współczynnika ściśliwości s równym odpowiednio 1/4, 1/5 oraz 1/6. Tym współczynnikom ściśliwości odpowiadają końcowe równania filtracji według zapisów 28, 35 oraz 42. Odnośne końcowe równania filtracji zostały wyprowadzone na podstawie ogólnego równania filtracji według zapisu 3 dla szczególnego przypadku stałego przepływu według zapisu 6.

Ogólnie równanie filtracji według zapisu 3, wyprowadzone z ogólnego równania Darcy’ego przepływu płynu przez warstwę porowatą (Ciborowski 1965; Dahlstrom i Nickolaus 1956; Hertjess 1948; Hertjess i Haas 1949; Le Lec 1962; Palica i in. 2008; Rodziewicz i in. 2011; Wiśniewski i in. 2013) według zapisu 1 zostało dla przekształconej postaci w zapisie 6 rozwiązane przy założeniu, że występujące w mianowniku ciśnienie jest ciśnieniem motorycznym procesu, a więc tym samym ciśnieniem do którego odnosi się licznik w równaniu wyjściowym według zapisu 3 - to jest określone nowe podejście $\mathrm{w}$ analizie teoretycznej procesu, które zostało przedstawione już w innych wcześniejszych publikacjach m.in. (Piecuch i in. 2013; Piecuch 2009, 2010).

Niniejsza publikacja jest kontynuacją rozważań przedstawionych w pracy (Piecuch i in. 2013), w której wyprowadzono równania filtracji o stałym przepływie dla osadu o dużej ściśliwości, a więc takiej dla której współczynnik ściśliwości so wyniósł odpowiednio 1/2, 1/3 oraz 2/3.

Przeprowadzona analiza teoretyczna wskazuje, że nie można sformułować jednego uniwersalnego równania filtracji, w którym występuje jako parametr współczynnik ściśliwości $\mathrm{s}_{\mathrm{O}}$ i za ten współczynnik do takiego jednego równania można podstawiać liczbową wartość tego współczynnika i wyliczać przepływ medium w tym procesie. Dla każdej nowej wartości współczynnika ściśliwości s $\mathrm{s}_{\mathrm{O}}$ trzeba wyprowadzić dla takiego szczególnego przypadku nowe równanie filtracji, jak tu przykładowo przedstawione końcowe równania w zapisie 28,35 oraz 42.

W praktyce inżynierskiej tego typu filtrację mieszanin przez siatkę filtracyjną można spotkać w filtrach próżniowych lub ciśnieniowych w zakładach przeróbki mechanicznej kopalń węgla lub rud w obiegach wodno-mułowych (Palica i in. 2007, 2009, 2010a, 2010b; Palica i Kocurek 2001, 2003; Piecuch 2010; Sówka i Piecuch 1974). 


\section{FILTRATION FORMING THE SEDIMENT OF LOW COMPRESSIBILITY ON THE MESH FILTER}

$$
\text { Key words }
$$

theoretical analyses, filtration process, sediment compressibility

\section{Abstract}

The publication shows a method of determining the final equations of the filtration process at a $\mathrm{V} / \mathrm{t}$ constant flow for different values of $\mathrm{s}_{\mathrm{O}}$ compressibility co-efficient equal $1 / 4,1 / 5$ and 1/6, respectively. These compressibility co-efficients correspond to the final equations of filtration for records 28, 35 and 42. The relevant final equations of filtration were derived based on the general equation of filtration by record number 3 for the special case of a constant flow by record 6 .

In general, the equation of filtration by record 3, derived from the general Darcy equation of fluid flow through the porous layer (Ciborowski 1965; Dahlstrom and Nickolaus 1956; Hertjess 1948; Hertjess and Haas 1949; Le Lec 1962; Palica et al. 2008; Rodziewicz et al. 2011; Wiśniewski et al. 2013) by record 1 , has been for the transformed form of a record 6 solved, assuming that the pressure occurring in the second part of the denominator is the process motor pressure, and thus the same pressure, to which refers the numerator in the equation by record 3 - this is a new approach defined in the theoretical analysis process that has already been shown in earlier publications, such as (Piecuch et al. 2013; Piecuch 2009, 2010).

The present publication is a continuation of the considerations described in (Piecuch et al. 2013), wherein the filtering equation is derived as a constant flow for sediment with a high compressibility, and therefore such for which a compressibility co-efficient $s_{O}$ amounted to $1 / 2,1 / 3$, and 2/3, respectively.

The conducted analysis of theoretical points indicates that one universal equation of filtration, in which compressibility co-efficient $\mathrm{s}_{\mathrm{O}}$ occurs as a parameter cannot be made and for that co-efficient into this equation one can substitute the numerical value of this co-efficient and calculate the flow of fluid in this process. For each new value of the compression co-efficient $\mathrm{s}_{\mathrm{O}}$, new equation of filtration, as exemplified here the final equation shown in the records 28,35 and 42 , has to be derived for this particular case.

In engineering practice, this type of mixtures filtration through a mesh filter can be found in pressure or vacuum filters in processing plants of coal mines or ores in water and mud circuits (Palica et al. 2007, 2009, 2010a, 2010b; Palica and Kocurek 2001, 2003; Piecuch 2010; Sówka and Piecuch 1974). 
